\title{
ANR and Cooperative Extension touch people's lives
}

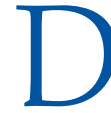

uring my first months as president of the University of California, I traveled around the state, educating myself on the workings and wonders of the UC system. One of my goals was to learn how the university serves the people of Cali-

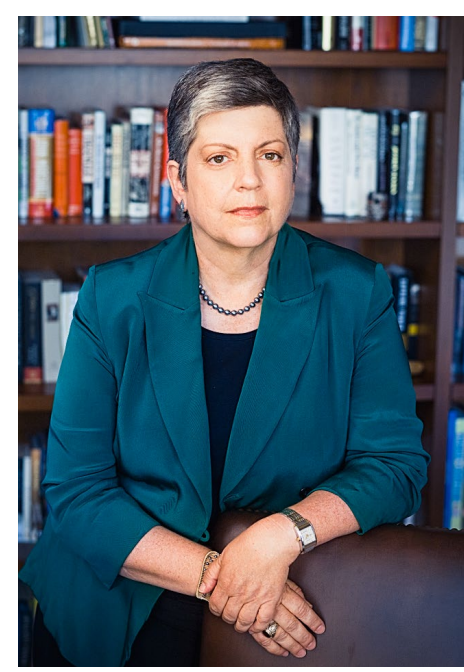

Janet Napolitano

President, University of California fornia and what we can do to enhance that public service.

At every stop, I saw outstanding examples of the ways UC enriches the lives, and livelihoods, of Californians. I visited labs where they're mapping the human brain, developing new battery technologies for electric and hybrid cars and studying ways to eradicate malaria. I was impressed with how UC's research discoveries not only drive the state's economy but also create opportunities for people who live far beyond California's borders. I developed a motto to capture the essence of what UC does: "Teaching for California, researching for the world."

UC's Division of Agriculture and Natural Resources (ANR) has its own mantra: "California roots, global reach." They both promote the same principle - we are dedicated to serving California and that service has impacts throughout the world.

One of the most profound ways in which UC touches people's lives is through the work of ANR and Cooperative Extension. Whether you are a backyard gardener or a major grower in the Central Valley, a

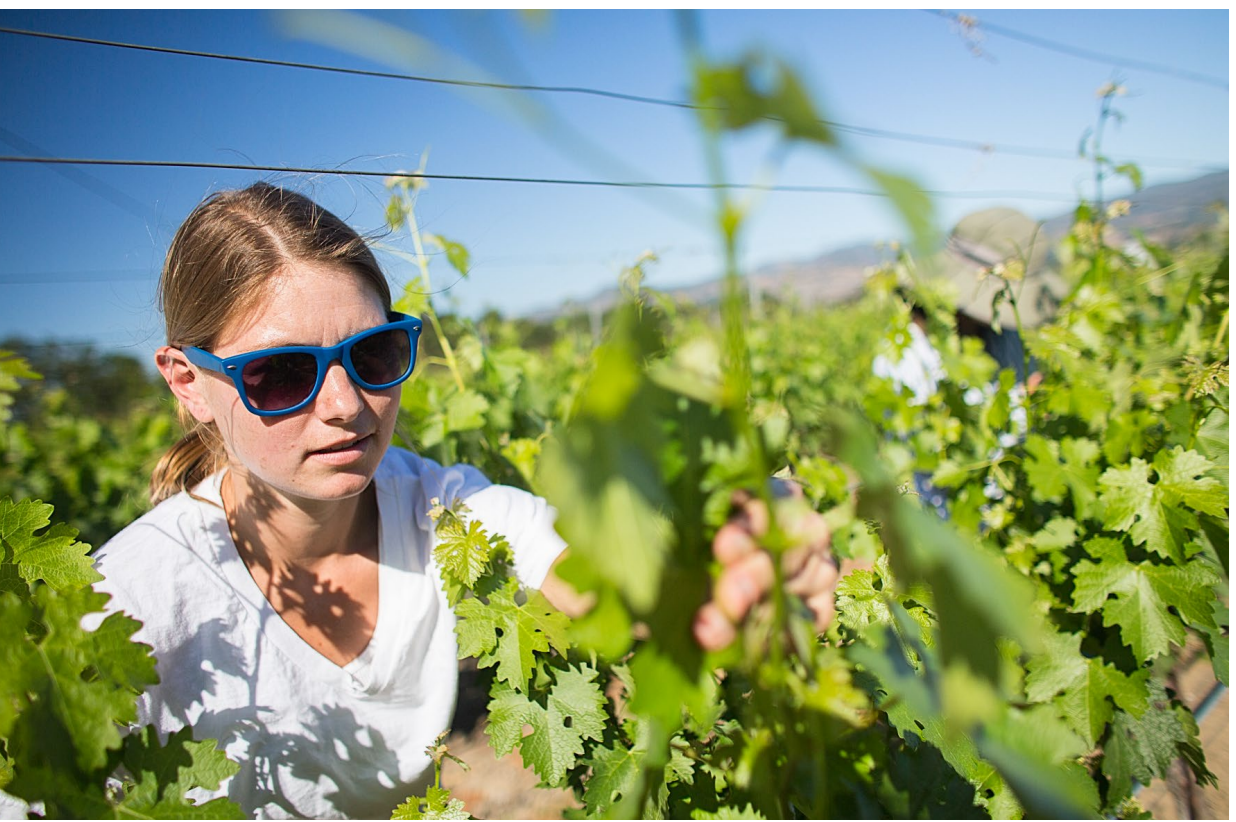

devotee of the California food and wine revolution or someone who simply strives to put nutritional meals on the table, chances are you have benefited from ANR, its research stations and the thousands of Cooperative Extension staff operating throughout the state.

\section{Moving forward}

I am proud to be a part of this great enterprise of public service, especially during the centennial year of the founding of the national Cooperative Extension system. As our nation celebrates this milestone, it is an appropriate time to honor the history of UC's agricultural roots and to move forward with new ways of serving California.

To that end, I am making a change that will accomplish both at once. Historically, the ANR vice president reported directly to the UC president, just as the campus chancellors do. In recent years, the division was put under the umbrella of the Office of the Provost. It is time to restore ANR to its traditional place in the administrative structure of the university. Accordingly, ANR will once again report directly to the president. I believe this change properly reflects the importance of the work ANR does for the UC system and the state of California. It will ensure that agricultural issues remain front and center to the work of the University of California and will allow me to stay in better touch with the agricultural community.

\section{Deep roots}

As a land-grant university, UC has always had a mandate to educate people in the latest agricultural methods. From the earliest days of the university, that was part of our mission.

When the Smith-Lever Act of 1914 created the national Cooperative Extension system, UC's mission expanded. The name Cooperative Extension itself embodies what that mission was intended to be and what it has evolved into.

"Extension" in this sense means reaching out and sharing the scientific knowledge of the university with the public. "Cooperative" is the key concept that makes these endeavors successful. With federal support, UC Cooperative Extension (UCCE) thrives as a partnership of growers, ranchers, state and local government and a committed community of ANR scientists, educators and employees. Together, this partnership has built California agriculture into a $\$ 45$ billion industry.

In celebration of the 100th anniversary of Cooperative Extension, this issue of California Agriculture highlights some of the many UCCE 
contributions to California. In these pages, you can read how a Fresno County CE advisor helped alfalfa seed growers stave off infestations of Africanized bees and increase crop yields.

In another example of the value of partnerships, you can learn how an advisor, a grower, an agriculture commissioner and a retired army officer teamed up to create a popular tourist destination and applegrowing region in a Northern California community whose orchard livelihood once faced extinction.

These are just two examples of how UCCE has come through in a crisis. Every day, its researchers and advisors apply scientific innovations to the challenges of increasing yields, battling invasive pests and diseases, reducing energy use, conserving water, breeding new crop varieties and developing sustainable farming methods.

Over the years, the Cooperative Extension mission has evolved with the times, and it will keep evolving. For example, during World Wars I and II, UCCE helped Californians plant victory gardens to increase the wartime supply of fresh produce. Today, UCCE runs Master Gardener programs in 45 counties, teaching people to enrich their homes and communities with sustainable, edible and ornamental gardens.

California 4-H still provides young people with the opportunities to raise livestock and compete at county fairs. Now, its programs have expanded to include technical knowledge with robot-building competitions and computer training classes.

Particularly noteworthy is the role UCCE and ANR play in building healthier communities. Through nutrition programs in underserved rural and urban neighborhoods, UCCE is fighting obesity, diabetes, high blood pressure and other chronic conditions

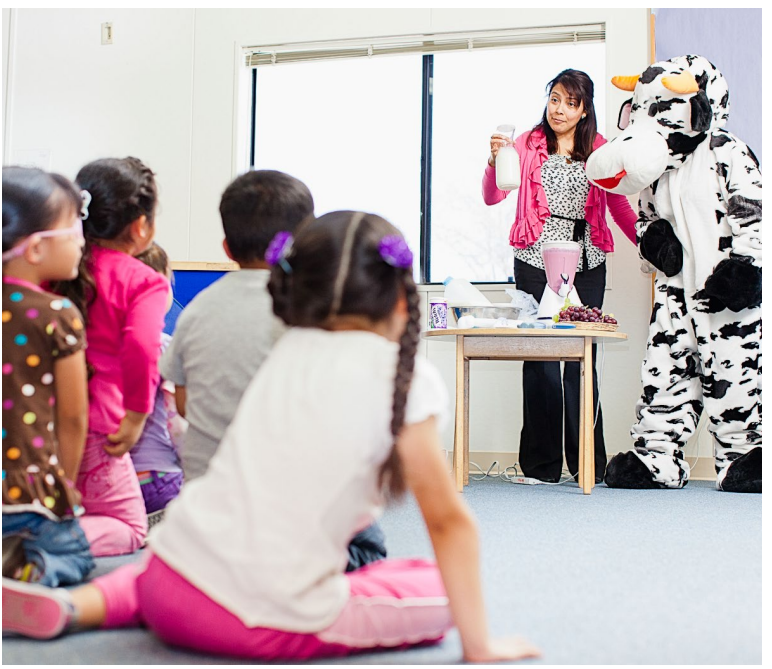

related to diet. These efforts benefit all Californians by helping curb rising health care costs.

\section{Critical responses}

With every crisis California faces, UCCE comes through with practical, on-the-ground solutions. With our state now facing a drought, ANR is committed to using its expertise to help our agriculture industry survive. We all know California is no stranger to the cycles of dry years and water rationing. ANR advances in irrigation, plant breeding and conservation methods helped our state survive droughts of the past. And we can do it again.

Climate change is the latest challenge in the water shortage difficulties facing our state. The effects of a warming environment on California's fields, forests and wildlife has risen to the top of the University's research concerns. While UC scientists study the causes and effects of climate change, UCCE will be applying that knowledge to technological innovations that will supply California with the latest drought survival strategies.

\section{Advocating}

A few months ago, I met with the President's Advisory Commission on Agriculture and Natural Resources for the first time, and I'm looking forward to meeting with that group again in April. I plan to work closely with its members to ensure that ANR has the tools to meet the needs of California.

When I was appointed UC's 20th president, I pledged to be the best advocate possible for the University of California. I am eager to be a partner with — and advocate for - ANR and all its valuable programs. In essence, that means I will be an advocate for California agriculture.

I'll be looking for opportunities to talk about all the ways the ANR family makes life better for California families. Don't be surprised if I call on you to help spread the word.

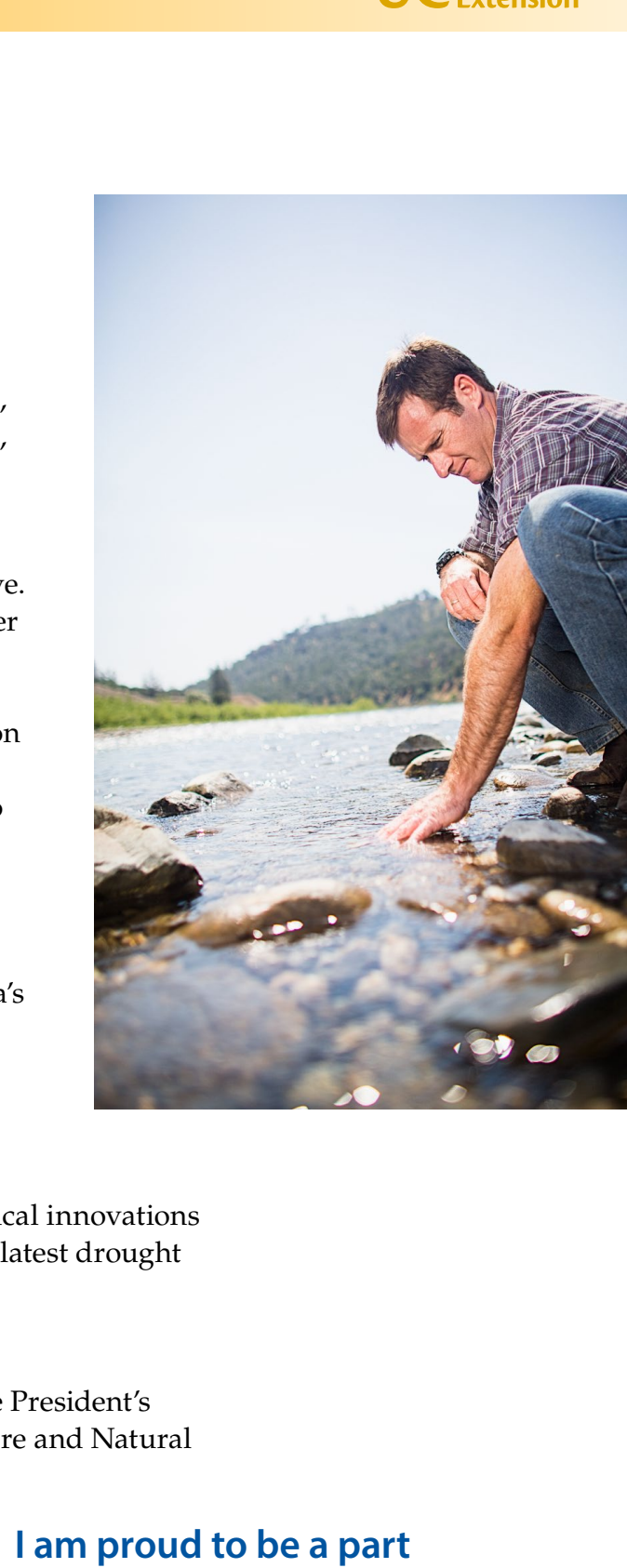

of this great enterprise of public service, especially during the centennial year of the founding of the national Cooperative Extension system. 